\title{
Mediterranean Journals
}

Integrative Journal of Medical Sciences

2021, Volume 8, ID 406

DOI: $\underline{\text { 10.15342/ijms.2021.406 }}$

\section{LETTER TO THE EDITOR}

\section{An MRI of Olfactory Tract in a Case of Post-COVID-19 Persistent Anosmia}

\author{
Amal Hajjij* a (D), Najwa Benslima* b (D) ; Jehanne Aasfara ${ }^{\mathrm{c}}$; Hatim Bensouda ${ }^{\mathrm{a}}$; Mohammed Mahi ${ }^{\mathrm{b}}$; Fouad Benariba ${ }^{\text {a }}$ \\ *Contributed equally to this work \\ ${ }^{a}$ Department of Otolaryngology, Head and Neck Surgery, Cheikh Khalifa International University Hospital, Faculty of Medicine, \\ Mohammed VI University of Health Sciences (UM6SS), Casablanca, Morocco. \\ ${ }^{\mathrm{b}}$ Department of Radiology, Cheikh Khalifa International University Hospital, Faculty of Medicine, Mohammed VI University of Health \\ Sciences (UM6SS), Casablanca, Morocco. \\ ${ }^{\mathrm{c}}$ Department of Neurology, Cheikh Khalifa International University Hospital, Faculty of Medicine, Mohammed VI University of Health \\ Sciences (UM6SS), Casablanca, Morocco. \\ ${ }^{\mathrm{d}}$ Department of Otolaryngology, Head and Neck Surgery, Mohammed V Military Training Hospital, Mohamed V University, Rabat, \\ Morocco.
}

KEYWORDS: Anosmia, Hyposmia, COVID-19, MRI, Olfactory Tract, Imaging.

Correspondence: Najwa Benslima, Department of Radiology, Cheikh Khalifa International University Hospital, Faculty of Medicine, Mohammed VI University of Health Sciences (UM6SS), Casablanca, Morocco.

Email:najwabenslima@gmail.com

Copyright $\odot 2021$ Hajjij A et al. This is an open access article distributed under the Creative Commons Attribution 4.0 International, which permits unrestricted use, distribution, and reproduction in any medium, provided the original work is properly cited.

The disease caused by the 2019 new coronavirus (2019$\mathrm{nCoV}$ ) was named coronavirus disease-19 (COVID-19) by the World Health Organization in February 2020. This infection is caused by severe acute respiratory syndrome coronavirus 2 (SARS-CoV-2), which is phylogenetically related to severe acute respiratory syndrome-coronavirus (SARS-CoV) [1]. It has been shown that 2019-nCov enters the cell through the ACE2 cell receptor in the same way as the severe acute respiratory syndrome (SARS) coronavirus [2].

China reported emergence of the new coronavirus disease in December 2019, therefore the COVID-19 had spread rapidly across 220 countries worldwide. As of November 21, 2020, more than 58.2 million people have been infected with SARS-Cov-2, and over 1.3 million deaths have been documented globally (3). In Morocco, the first cases have been diagnosed on March 2, 2020 (4). As of January 10, 2021, a total of 451637 cases have been diagnosed, with 7709 corresponding deaths (4).

Peng Zhou et al. identified and characterized the novel coronavirus (SARS-CoV-2) in the journal Nature on February 32020 (5). The authors also confirmed that
SARS-CoV-2 used the same receptor, angiotensin converting enzyme 2 (ACE2), as SARS-CoV to enter the cell. In a report that has not yet been peer-reviewed, it is claimed that the number and proportion of ACE2expressing cells in nasal and oral tissue are comparable to the corresponding cells in lung tissue and in the colon (6, 7 ), and the authors wonder whether nasal and oral tissue may be the first to be infected by SARS-CoV-2 (6). These results are partly supported by another publication that showed that the ACE2 receptor was expressed on the oral mucosa, especially on the epithelial cells of the tongue (8). In the latter, non-peer-reviewed report, it is claimed that olfactory epithelial support cells, stem cells, and nasal respiratory epithelium express two genes that are involved in the transport of SARS-CoV-2 into the cell, namely ACE2 and TMPRSS2, and that these may be potential mechanisms whereby SARSCoV-2 infection can lead to anosmia (9).

Since the first publications presuming that anosmia/ hyposmia, even without associated respiratory symptoms, should consider the diagnosis of COVID-19 $(10,11)$, these symptoms have been increasingly recognized as symptoms 
of COVID-19 disease either isolated or associated to respiratory and general symptoms (12). In terms of prevalence, a large study of 417 patients with mild-tomoderate COVID-19, found $85.6 \%$ olfactory dysfunction (13). In a metaanalysis of Hoang et al, $45 \%$ of COVID-19 patients had olfactory dysfunction (14).

In this case of a 21 years old patient, without any known comorbidities, presenting persisting anosmia one month after SARS-Cov-2 infection. The patient had a mild form of COVID-19 and reported a persistent anosmia one month after a negative RT-PCR nasopharyngeal test of SARS-
Cov-2. Using brain magnetic resonance imaging (MRI), we studied the olfactory region (bulb, tract, gyrus rectus, and orbital cortex) with the following sequences: 2dimentional T2 weighted, 3-dimentional T2 fluidattenuated-inversion-recovery (FLAIR), and coronal image of fast spin echo gradient T2 weighted. The MRI studied the volume of the olfactory bulb and the signal intensity of the olfactory cortex. It predicts the prognosis and differential diagnosis. In our case, we didn't find any abnormality of signal or morphology of olfactory region, neither in the sinuses and nasal cavities (FIGURE 1).
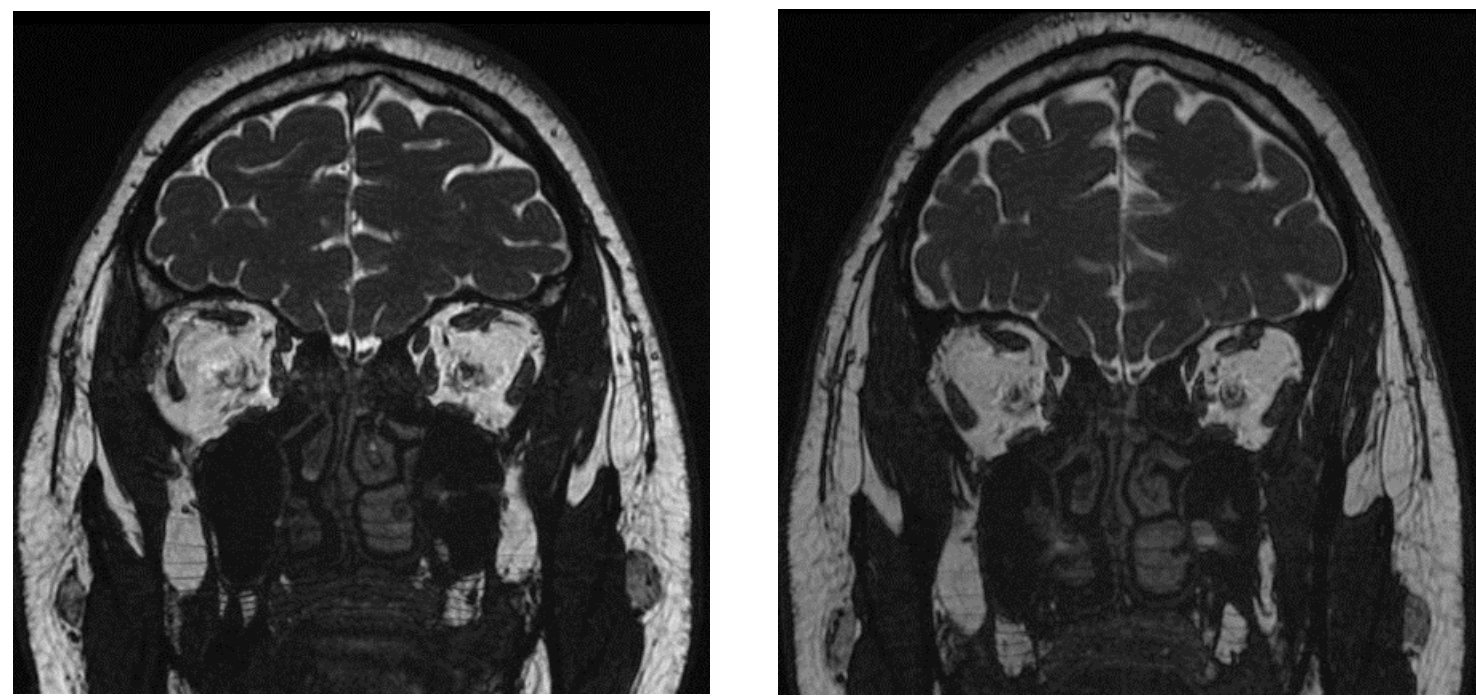

Figure 1: Coronal T2 (fast spin echo with saturation of fat signal) reconstruction of MR images in a 20 years old man presenting persisting anosmia after Covid-19s' pneumonia, showing normal morphology and signal of the olfactory bulb without nasal congestion (arrows). There is also a normal signal of the olfactory cortex.

Some previous publications $(15,16)$ founded in 4 of 12 patients a cortical hyper intensity in the gyrus rectus and olfactory bulbs at the critical phase of infection and disappeared after healing. This finding suggested edema and inflammation of the olfactory tract. Multiple areas (> 2) of olfactory bulb contour lobulation, rectangular shape or atrophic appearance were considered as abnormal (17). These findings suggest that virus invasion of the olfactory region could be explored by imaging if done at an appropriate delay from the onset of symptoms. However, earlier publications (18) reported normal morphology and signal intensity of the olfactory region in post-viral anosmia.

Finally, future prospective studies that examine the migration path and timing of SARS-CoV-2 are needed in order to determine the ideal timing for realizing an MRI so as to possibly find an abnormal signal on the olfactory bulb.

\section{ABBREVIATIONS}

FLAIR: Fluid-Attenuated-Inversion-Recovery

MRI: Magnetic Resonance Magnetic

\section{AUTHORS' CONTRIBUTIONS}

The participation of each author corresponds to the criteria of authorship and contributorship emphasized in the Recommendations for the Conduct, Reporting, Editing, and Publication of Scholarly work in Medical Journals of the International Committee of Medical Journal Editors. Indeed, all the authors have actively participated in the redaction, revised the manuscript, and provided approval for this final revised version.

\section{PATIENT'S CONSENT}

Written informed consent was obtained from the patient for the publication of this case report. 


\section{REFERENCES}

[1] Gorbalenya A (2020) The species severe acute respiratory syndrome-related coronavirus: classifying 2019-nCoV and naming it SARS-CoV-2. Nat Microbiol. DOI: $10.1038 / \mathrm{s} 41564-020-0695-\mathrm{Z}$

[2] Letko MC, Munster V (2020) Functional assessment of cell entry and receptor usage for lineage $\mathrm{B} \beta$-coronaviruses, including 2019-nCoV. bioRxiv

[3] WHO. WHO Coronavirus Disease (COVID-19) Dashboard, 2020. Available: https://covid19.who.int

[4] Ministry of Health of Morocco, 2020. Rabat, Morocco. https://www.sante.gov.ma/

[5] Zhou P, Yang XL, Wang XG et al. A pneumonia outbreak associated with a new coronavirus of probable bat origin. Nature 2020; 579: 270-3.

[6] Wu C, Zheng M. Single-cell RNA expression profiling shows that ACE2, the putative receptor of COVID-2019, has significant expression in nasal and mouth tissue, and is co-expressed with TMPRSS2 and not co-expressed with SLC6A19 in the tissues. Preprint. https://www.researchsquare.com/article/rs-16992/v1 Accessed 29.3.2020.

[7] Wu C, Zheng M. Single-cell RNA expression profiling shows that ACE2, the putative receptor of Wuhan 2019$\mathrm{nCoV}$, has significant expression in the nasal mouth, lung and colon tissues, and tends to be co-expressed with HLADRB1 in the four tissues. Preprints 2020.

[8] $\mathrm{Xu} \mathrm{H}$, Zhong L, Deng $\mathrm{J}$ et al. High expression of ACE2 receptor of 2019-nCoV on the epithelial cells of oral mucosa. Int J Oral Sci 2020; 12: 8.

[9] Brann DH, Tsukahara T, Weinreb C et al. Non-neural expression of SARS-CoV-2 entry genes in the olfactory epithelium suggests mechanisms underlying anosmia in COVID-19 patients. bioRxiv 2020. DOI: $10.1101 / 2020.03 .25 .009084$

[10] Hopkins C and Kumar N (2020) Loss of sense of smell as marker of COVID-19 infection ENT UK LINK
[11] Rabin R (2020) Lost sense of smell may be peculiar clue to coronavirus infection The New York Times [https://www.nytimes.com/2020/03/22/health/coronavirus -symptoms-smell-taste.html]

[12] Cooper KW, Brann DH, Farruggia MC, et al. COVID-19 and the chemical senses: supporting players take center stage. Neuron 2020; 107:219-233.

[13] Lechien, J.R., Chiesa-Estomba, C.M., De Siati, D.R. et al. Olfactory and gustatory dysfunctions as a clinical presentation of mild-to-moderate forms of the coronavirus disease (COVID-19): a multicenter European study. Eur Arch Otorhinolaryngol 277, 2251-2261 (2020). DOI: $10.1007 / \mathrm{s} 00405-020-05965-1$

[14] Hoang MP, Kanjanaumporn J, Aeumjaturapat S, et al. Olfactory and gustatory dysfunctions in COVID-19 patients: a systematic review and metaanalysis. Asian Pac J Allergy Immunol 2020; 38:162-169.

[15] Letterio S. Politi, Ettore Salsano, Marco Grimaldi, Magnetic Resonance Imaging Alteration of the Brain in a Patient With Coronavirus Disease 2019 (COVID-19) and Anosmia. JAMA Neurol. 2020; 77(8):1028-1029. DOI: 10.1001/jamaneurol.2020.2125

[16] S.B Strauss, J.E Lantos, L.A Heier, D.R Shatzkes, C.D Phillips (2020). Olfactory Bulb Signal Abnormality in Patients with COVID-19 Who Present with Neurologic Symptoms. American Journal of Neuroradiology. DOI: 10.3174/ajnr.a6751

[17] Kandemirli et al. Olfactory Bulb MRI and Paranasal Sinus CT Findings in Persistent COVID-19 Anosmia. Acad Radiol 2020. DOI: $\underline{10.1016 / j . a c r a .2020 .10 .006}$

[18] Galougahi, M. K., Ghorbani, J., Bakhshayeshkaram, M. Naeini, A. S., \& Haseli, S. (2020). Olfactory Bulb Magnetic Resonance Imaging in SARS-CoV-2-Induced Anosmia: The First Report. Academic Radiology. DOI: $10.1016 /$ j.acra.2020.04.002 